Article

\title{
Compliance with the 2018 World Cancer Research Fund/American Institute for Cancer Research Cancer Prevention Recommendations and Prostate Cancer
}

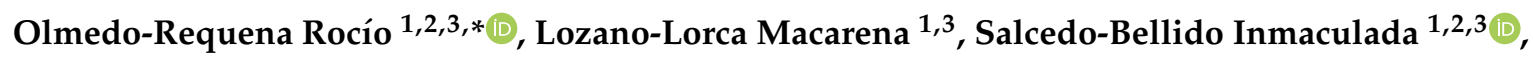 \\ Jiménez-Pacheco Antonio ${ }^{4}$, Vázquez-Alonso Fernando ${ }^{5}$, García-Caballos Marta ${ }^{6}$, \\ Sánchez María-José 1,2,3,7 (D) and Jiménez-Moleón José-Juan 1,2,3 (D) \\ 1 Department of Preventive Medicine and Public Health, University of Granada, 18016 Granada, Spain; \\ macarenalozano@ugr.es (L.-L.M.); isalcedo@ugr.es (S.-B.I.); \\ mariajose.sanchez.easp@juntadeandalucia.es (S.M.-J.); jjmoleon@ugr.es (J.-M.J.-J.) \\ 2 Consortium for Biomedical Research in Epidemiology and Public Health (CIBERESP), 28029 Madrid, Spain \\ Instituto de Investigación Biosanitaria (ibs.GRANADA), 18014 Granada, Spain \\ 4 Urology Department, San Cecilio University Hospital, 18016 Granada, Spain; anjipa29@hotmail.com \\ 5 Urology Department, Virgen de las Nieves University Hospital, 18014 Granada, Spain; \\ fvazquezalonso@gmail.com \\ 6 Cartuja Primary Health Care Centre, Distrito Sanitario Granada-Metropolitano, 18013 Granada, Spain; \\ martagc81@gmail.com \\ 7 Andalusian School of Public Health (EASP), 18011 Granada, Spain \\ * Correspondence: rocioolmedo@ugr.es; Tel.: +34-958243543
}

Received: 22 January 2020; Accepted: 11 March 2020; Published: 14 March 2020

Abstract: The etiology of prostate cancer (PCa) remains largely unknown. Compliance with the 2018 World Cancer Research Fund/American Institute for Cancer Research (WCRC/AICR) cancer prevention recommendations and its relationship to PCa was evaluated. A total of 398 incident PCa cases and 302 controls were included. The selection criteria for both cases and controls were: (i) age between 40-80 years; and (ii) residence in the coverage area of the reference hospitals for 6 months or more prior to recruitment. A score to measure the compliance with the recommendations of 2018 WCRC/AICR criteria was built. The level of compliance was used as a continuous variable and categorized in terciles. The aggressiveness of PCa was determined according to the ISUP classification. Adjusted odds ratios (aOR) and their 95\% confidence intervals $(95 \% \mathrm{CI})$ were estimated using multivariable logistic regression models. A slight protective tendency was observed between the level of compliance with the preventive recommendations and PCa risk, aOR $=0.81(95 \% \mathrm{CI}$ 0.69-0.96) for the total cases of PCa. This association also was observed when the aggressiveness was considered. In addition, limiting consumption of "fast foods", sugar-sweetened drinks, and alcohol were independently associated with lower risk of PCa.

Keywords: prostate cancer; WCRF/AICR 2018 recommendations; nutrition-based guidelines; case-control study

\section{Introduction}

Prostate cancer (PCa) is the most common cancer in men, and has the highest incidence and the third highest mortality, after lung and colorectal cancer, in Europe [1]. In recent years, the incidence of PCa has become widespread in all countries [2], with around 450,000 estimated new cases per year [3]. This increase may be related to population aging and new exposures, or higher levels of exposure, to environmental risk factors, together with the massive use of screening for prostate-specific antigen (PSA) and diagnostic techniques [4]. 
Despite its considerable impact, the etiology of PCa remains largely unknown, and only the following risk factors are considered as well-established: age, ethnicity [2], hereditary factors, and genomic [5-7]. All of these are non-modifiable factors. Other factors related to adherence to unhealthy lifestyles have been proposed, such as poor quality of the diet, physical inactivity or sedentariness, and obesity, but their individual roles in the etiology of PCa remains unclear [8-10]. Regardless of the relationship between diet, physical activity, and body weight and PCa, these factors have been associated with other types of cancer such as breast or colorectal cancer [11,12]. Therefore, it could be interesting to explore the relationship between the combination of these three factors and the risk of PCa.

In 2007, the World Cancer Research Fund (WCRF) and the American Institute for Cancer Research (AICR) published the Second Expert Report for cancer prevention, replacing the First Expert Report conducted in $1997[13,14]$. This report included a total of 10 recommendations related to diet, physical activity, and body fatness for the prevention of cancer. However, these recommendations did not establish a quantitative standard system to manage them, this complicates the comparison between studies. In 2018, the Third Expert Report was published (Diet, Nutrition, Physical Activity, and Cancer: A Global Perspective) [15], and one year later a standardized scoring system was developed and published [16].

Since 2007, several studies have evaluated the association of the recommendations of the Second Expert Report and cancer mortality [17], as well as the risk of developing cancer [18]; especially with breast cancer, colorectal cancer, head and neck cancer, pancreatic cancer, lymphocytic leukemia, and PCa [19-31]. However, as we have commented previously, the comparison of the results is not easy because of the absence of standard criteria. Furthermore, the association between 2018 WCRF/AICR Cancer Prevention Recommendations and PCa has not yet been studied. In addition, PCa may not be a single pathology, and its behavior may be different depending on the degree of aggressiveness. Overdiagnosis poses a fundamental problem, especially in low aggressive cases [32]. Therefore, it is necessary to evaluate the new standardize recommendations and their association with PCa taking into account the grade of aggressiveness. The aim of the present study is to evaluate the effect of compliance with the 2018 nutrition-based guidelines of the WCRF/AICR cancer prevention recommendations on the risk of PCa and its association with the aggressiveness at diagnosis.

\section{Materials and Methods}

\subsection{Study Design and Setting}

A population-based case-control study was developed to evaluate the association between lifestyles and PCa among Spanish men (CAPLIFE study). It was carried out at in two main University Hospitals in Granada (Spain): Virgen de las Nieves and San Cecilio Hospitals and their catchment area. They belong to Metropolitan Granada District, which covers more than 645,000 inhabitants. All those PCa cases that belonged to the aforementioned hospitals were invited to participate by their urologist after being diagnosed of PCa. Study participants were enrolled from May 2017 to December 2019.

Ethical Approval for this study was provided by the Ethics Committee of Biomedical Research of Andalusia in March 2017. All men included in the study were fully informed about the study objectives and they signed a written informed consent before their voluntary participation. Confidentiality of data is secured by removing personal identifiers in the dataset.

\subsection{Participants}

Eligible cases were required to meet the following criteria: (1) new diagnosis of PCa (International Classification of Diseases 10th Revision [ICD-10]: C61) [33] with histological confirmation. We have only included incident cases before starting any type of treatment for PCa; (2) age between 40 and 80 years; (3) residence in the coverage area of the reference hospitals for 6 months or more prior to recruitment. The same criteria were used for controls, except diagnosis of PCa. The incident cases 
were selected from the Urology Department of the participating hospitals, using the Pathological Anatomy listings and checking the new positive biopsies for PCa. Controls were randomly selected from the population lists assigned to general practitioners of the primary care centers located in the catchment area of the hospitals from which the cases were selected (Granada-Metropolitan Sanitary District). The controls were matched to cases by age, with a maximum age difference of 5 years, based on information from the Granada Cancer Registry, a population-based cancer registry with data quality certified by the International Agency for Research on Cancer (http://cancergranada.org/es/index.cfm).

\subsection{Data Sources and Variables}

Data were collected between 2017 and 2019 by face-to-face interviews conducted by trained interviewers using a structured computerized epidemiological questionnaire. The same interviewers surveyed cases and controls. Information on the following background variables, for both cases and controls, was obtained: sociodemographic data (age, education level, occupation, and marital status), lifestyles (smoking status, alcohol consumption, physical activity, sleeps habits, and diet), and personal/family medical history, including first-degree family history of PCa in father and/or brothers, among other variables. Waist and hip circumference were measured at the interview, while height and weight one year prior to diagnosis were self-reported, and body mass index (BMI) calculated. If there were any missing data, it was recovered by reviewing the clinical record or via telephone contact.

The physical activity information was collected using the International Physical Activity Questionnaire (IPAQ), validated for the Spanish population [34]. In addition, subjects were provided with a semi-quantitative food frequency questionnaire (FFQ); also previously validated for the Spanish population [35] which included 134 foods, specifying the portion size for each of them, referring to the 12 months prior to diagnosis. Nutrient intakes were estimated using Spanish food composition tables [36]. In addition, this study included only subjects with plausible energy intakes. An intake of less than $800 \mathrm{kcal} /$ day and more than $4000 \mathrm{kcal} /$ day were considered as implausible extreme energy intakes [37].

\subsubsection{WCRF/AICR Score Construction}

The 2018 WCRF/AICR Cancer Prevention Recommendations includes a total of ten recommendations: (1) body fatness, (2) physical activity, (3) consumption of whole grains, vegetables, fruit, and beans, (4) fast food and other processed foods, (5) red and processed meat, (6) sugar-sweetened drinks, and (7) alcohol, (8) dietary supplements, (9) breastfeeding, and (10) cancer survivors' recommendations. In this study, we omitted the latest three recommendations. The reasons for avoiding the three last recommendations were the following: (i) The use of dietary supplements for cancer prevention and choice to consume nutrients through food alone is largely addressed through the other five dietary recommendations, as AICR refers in the article on the operationalizing of the score [16]; and (ii) the specific recommendation for cancer survivors and breastfeeding are not applicable to our population. Table 1 shows the goals for the ten recommendations and their operationalization.

Briefly, the method of estimating the score according to the standardized scoring system for 2018 WCRF/AICR cancer prevention recommendations [16] is based on the following criteria: 1 point was assigned when the recommendation was met, 0.5 points when it was partially met, and 0 points when not met. When the recommendation was composed of two subitems, such as body fatness and consumption of whole grains, vegetables, fruit, and beans recommendation, the scoring weight is divided equally between both to retain a total of one point $(0.5,0.25$, and 0 points for meeting, partially meeting, and not meeting each subitem, respectively). 
Table 1. The 2018 WCRF/AICR score construction in the CAPLIFE study.

\begin{tabular}{|c|c|c|c|}
\hline Components & Personal Recommendations (Goals) & Operationalization & Scoring \\
\hline \multirow{5}{*}{ 1. Have a healthy weight } & $\begin{array}{l}\text { Ensure that body weight during childhood and adolescence projects } \\
\text { toward the lower end of the healthy adult BMI range }\end{array}$ & No information for operationalization & n.a \\
\hline & $\begin{array}{c}\text { Keep your weight as low as you can within the healthy range } \\
\text { throughout life }\end{array}$ & $\begin{array}{l}\mathrm{BMI} \geq 18.5-<25 \mathrm{~kg} / \mathrm{m}^{2} \\
\mathrm{BMI} \geq 25-<30 \mathrm{~kg} / \mathrm{m}^{2}\end{array}$ & $\begin{array}{c}0.5 \\
0.25\end{array}$ \\
\hline & & $\begin{array}{c}\mathrm{BMI} \geq 30 \mathrm{~kg} / \mathrm{m}^{2} \text { or }<18.5-25 \mathrm{~kg} / \mathrm{m}^{2} \\
\text { WC }<94 \mathrm{~cm}\end{array}$ & $\begin{array}{c}0 \\
0.5\end{array}$ \\
\hline & Avoid weight gain (measured as body weight or waist circumference) & $\mathrm{WC} \geq 94-<102 \mathrm{~cm}$ & 0.25 \\
\hline & & $\mathrm{WC} \geq 102 \mathrm{~cm}$ & 0 \\
\hline \multirow{4}{*}{ 2. Be physically active } & & Total moderate-vigorous $\mathrm{PA} \geq 150 \mathrm{~min} /$ week & 1 \\
\hline & national guidelines & Total moderate-vigorous $\mathrm{PA} \geq 75-<150 \mathrm{~min} /$ week & 0.5 \\
\hline & & Total moderate-vigorous $\mathrm{PA}<75 \mathrm{~min} /$ week & 0 \\
\hline & Limit sedentary habits & No information for operationalization & n.a \\
\hline \multirow{8}{*}{$\begin{array}{l}\text { 3. Eat a diet rich in whole grains, } \\
\text { vegetables, fruit, and beans }\end{array}$} & & Dietary fiber intake $\geq 30 \mathrm{~g} /$ day & 0.5 \\
\hline & Consume a diet that provides at least $30 \mathrm{~g} /$ day of fiber from food sources & Dietary fiber intake $\geq 15-<30 \mathrm{~g} /$ day & 0.25 \\
\hline & & Dietary fiber intake $<15 \mathrm{~g} /$ day & 0 \\
\hline & $\begin{array}{l}\text { Include more foods containing wholegrains, non-starchy vegetables, } \\
\text { fruit, and pulses (legumes) such as beans and lentils }\end{array}$ & No information for operationalization & n.a. \\
\hline & Eat a diet high in all types of plant foods including at least five portions & Fruits and vegetables intake ${ }^{a} \geq 400 \mathrm{~g} /$ day & 0.5 \\
\hline & or servings (at least $400 \mathrm{~g}$ or $15 \mathrm{oz}$ in total) of a variety of non-starchy & Fruits and vegetables intake ${ }^{a} \geq 200-<400$ g/day & 0.25 \\
\hline & vegetables and fruit every day & Fruits and vegetables intake ${ }^{a}<200 \mathrm{~g} /$ day & 0 \\
\hline & $\begin{array}{l}\text { If you eat starchy roots and tubers as staple foods, eat non-starchy } \\
\text { vegetables, fruit, and pulses (legumes) regularly too if possible }\end{array}$ & No information for operationalization & n.a. \\
\hline \multirow{5}{*}{$\begin{array}{l}\text { 4. Limit consumption of "fast foods" and } \\
\text { other processed foods high in fat, } \\
\text { starches, or sugars }\end{array}$} & \multirow{5}{*}{$\begin{array}{c}\text { Limit consumption of processed foods high in fat, starches or sugars } \\
\text { including "fast foods", many prepared dishes, snacks, bakery foods and } \\
\text { desserts, and confectionery (candy) }\end{array}$} & Percent of total kcal from ultra-processed foods & \\
\hline & & (aUPFs): & 1 \\
\hline & & Tercile 1 & \\
\hline & & Tercile 2 & 0.5 \\
\hline & & Tercile 3 & 0 \\
\hline \multirow{3}{*}{$\begin{array}{l}\text { 5. Limit consumption of red and } \\
\text { processed meat }\end{array}$} & \multirow{3}{*}{$\begin{array}{l}\text { If you eat red meat, limit consumption to no more than about three } \\
\text { portions per week. Three portions are equivalent to about } 350 \text { to } 500 \mathrm{~g} \\
\text { (about } 12 \text { to } 18 \mathrm{oz} \text { ) cooked weight of red meat. Consume very little, } \\
\text { if any, processed meat. }\end{array}$} & $\begin{array}{c}\text { Red meat }<500 \mathrm{~g} / \mathrm{wk} \text { and processed meat } \\
<21 \mathrm{~g} / \mathrm{wk}\end{array}$ & 1 \\
\hline & & $\begin{array}{c}\text { Red meat }<500 \mathrm{~g} / \mathrm{wk} \text { and processed meat } \\
\geq 21-<100 \mathrm{~g} / \mathrm{wk}\end{array}$ & 0.5 \\
\hline & & Red meat $\geq 500 \mathrm{~g} / \mathrm{wk}$ or processed meat $\geq 100 \mathrm{~g} / \mathrm{wk}$ & 0 \\
\hline
\end{tabular}


Table 1. Cont.

\begin{tabular}{|c|c|c|c|}
\hline Components & Personal Recommendations (Goals) & Operationalization & Scoring \\
\hline $\begin{array}{l}\text { 6. Limit consumption of } \\
\text { sugar-sweetened drinks }\end{array}$ & Do not consume sugar-sweetened drinks & $\begin{array}{l}\text { Sugary drinks intake }{ }^{b}=0 \mathrm{~g} / \text { day } \\
\text { Sugary drinks intake } \mathrm{e}^{\mathrm{b}}>0-\leq 250 \mathrm{~g} / \text { day } \\
\text { Sugary drinks intake }{ }^{\mathrm{b}}>250 \mathrm{~g} / \text { day }\end{array}$ & $\begin{array}{c}1 \\
0.5 \\
0\end{array}$ \\
\hline 7. Limit alcohol consumption & For cancer prevention, it is best not to drink alcohol & $\begin{array}{c}\text { No ethanol intake }=0 \mathrm{~g} / \text { day } \\
\text { Current ethanol intake }>0-<28 \mathrm{~g} / \text { day } \\
\text { Current ethanol intake } \geq 28 \mathrm{~g} / \text { day }\end{array}$ & $\begin{array}{c}1 \\
0.5 \\
0\end{array}$ \\
\hline $\begin{array}{l}\text { 8. Do not use supplements for } \\
\text { cancer prevention }\end{array}$ & $\begin{array}{l}\text { High-dose dietary supplements are not recommended for cancer } \\
\text { prevention-aim to meet nutritional needs through diet alone }\end{array}$ & No information for operationalization & n.a \\
\hline $\begin{array}{l}\text { 9. For mothers: breastfeed your baby, } \\
\text { if you can }\end{array}$ & $\begin{array}{l}\text { This recommendation aligns with the advice of the World Health } \\
\text { Organization, which recommends infants are exclusively breastfed to } \\
6 \text { months, and then up to } 2 \text { years of age or beyond alongside appropriate } \\
\text { complementary foods. }\end{array}$ & Not applicable to this population & n.a. \\
\hline $\begin{array}{l}\text { 10. After a cancer diagnosis: follow our } \\
\text { recommendations if you can }\end{array}$ & $\begin{array}{l}\text { All cancer survivors should receive nutritional care and guidance on } \\
\text { physical activity from trained professionals. } \\
\text { Unless otherwise advised, and if you can, all cancer survivors are } \\
\text { advised to follow the Cancer Prevention Recommendations as far as } \\
\text { possible after the acute stage of treatment }\end{array}$ & $\begin{array}{l}\text { Not applicable to this study } \\
\text { Not applicable to this study }\end{array}$ & $\begin{array}{l}\text { n.a. } \\
\text { n.a. }\end{array}$ \\
\hline
\end{tabular}


In particular, for the recommendation on "fast foods" we selected all ultra-processed foods-according to the NOVA classification [38]-available in the FFQ. After excluding those items already included in other recommendations (i.e., processed meats, sweetened drinks, and alcoholic beverages), we calculated the proportion of calorie intake ( $\mathrm{kcal} /$ day) derived from ultra-processed foods (group 4 NOVA classification) with respect to the total caloric intake per day. The ratio of fast food caloric intake divided by total caloric intake was finally broken down into terciles according to its distribution in the control group.

The score of each recommendation was added to obtain the total score, which ranged from a minimum value of 0 to a maximum value of 7 points, with higher values indicating high compliance with the cancer prevention recommendations. From the score obtained for the control group, the cut-off points of the terciles were established and applied to both groups to define the level of compliance: (i) Tercile 1: minimal compliance with the recommendations; (ii) Tercile 2: intermediate compliance and; (iii) Tercile 3: minimum compliance.

\subsubsection{Measurement of Tumor Aggressiveness}

The Gleason score was collected from the pathological report of each participant. It assigns two grades for each patient: a primary grade is given to describe the cells that make up the largest area of the tumor and a secondary grade is given to describe the degree of differentiation of the cells of the next largest area. Both grades use values from 1 to 5 : 1 for a high degree of differentiation and 5 for a minimal degree of differentiation [39]. The aggressiveness of the tumor was determined according to the classification of the International Society of Urological Pathology (ISUP) [40], which establishes the existence of five grade groups that are: (i) ISUP 1 (Gleason $3+3$ ); (ii) ISUP 2 (Gleason $3+4$ ); (iii) ISUP 3 (Gleason $4+3$ ); (iv) ISUP 4 (Gleason 8); and (v) ISUP 5 (Gleason $>8$ ). From this, two categories of aggressiveness were constructed: low aggressiveness (ISUP 1,2) and high aggressiveness (ISUP 3, 4, 5) [41].

\subsection{Statistical Analysis}

Characteristics of the participants were examined using means and standard deviations (SD) for continuous variables and percentages for categorical variables. These characteristics were described for case and control groups as well as 2018 WCRF/AICR terciles for the control group. Chi-squared tests were used to evaluate the level of significance of the differences observed in categorical variables, and Student's t-tests or one-way ANOVA for continuous variables.

Multivariable logistic regression models were used to estimate odds ratios (OR) and 95\% confidence intervals $(95 \% \mathrm{CI})$ for the association between the 2018 WCRF/AICR recommendations and PCa. The $2018 \mathrm{WCRF} / \mathrm{AICR}$ score was analyzed as a continuous variable (one-unit increment) and as a categorical variable through the terciles. The first tercile was used as the reference category (minimum compliance with the cancer prevention recommendations). We used the information from previous studies and directed acyclic graph (DAG) to identify potential confounders; thus, epidemiological and statistical criteria were used to construct the models. An adjusted model was constructed including as covariates: age, educational level, smoking status, primary family history of PCa, and total energy intake. In addition, analyses were also conducted stratifying by aggressiveness: low aggressiveness and high aggressiveness. We estimated the individual association of each component of the 2018 WCRF/AICR score with PCa risk, after adjustment for all other components of the score and the aforementioned potential confounders. For this analysis, participants without information on anthropometric measures, physical activity, or dietary information were excluded. People with implausible energy intake values were also excluded for the analysis. All statistical tests were two-sided and statistical significance was set at $p<0.05$. Statistical analyses were performed using statistical program Stata v.15 (Stata Corp., College Station, TX, USA, 2017). 


\section{Results}

Figure 1 shows the flow-chart diagram for the participants in the CAPLIFE study until December 2019. A total of 398 PCa cases and 302 controls had complete information for the 2018 WCRF/AICR score and a plausible total energy intake. There were no statistically significant differences between controls with and without information on the score and PCa cases with and without the score, except for the educational level in PCa cases (Supplementary Table S1).

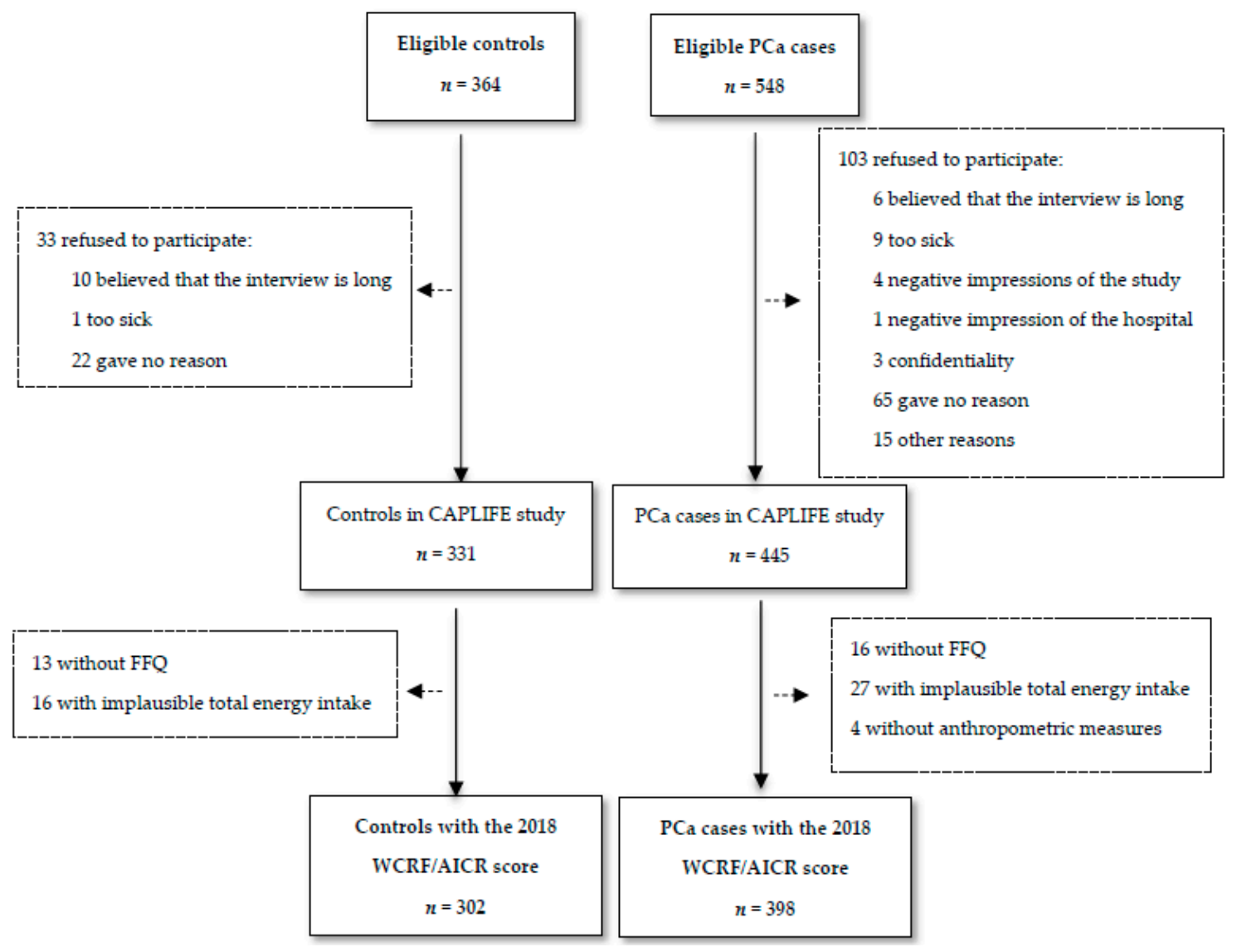

Figure 1. Flow-chart CAPLIFE study.

Distribution characteristics between cases and controls are shown in Table 2. Compared with controls, PCa cases were slightly older, 67.7 (SD 7.4) vs. 65.3 (8.2) years, they had a higher alcohol consumption (16.8 for cases vs. 10.3\% for controls) and a higher energy intake, 2511.8 (SD 705.7) vs. 2438.1 (SD 617.6) kcal/day. More than three quarters of the PCa cases were of low aggressiveness $(77.1 \%)$ cases with an ISUP of 1 or 2 . In terms of compliance with the 2018 WCRF/AICR score, this was slightly lower in the PCa cases than in controls, 3.27 (DS 0.93) vs. 3.42 (DS 1.01) points, respectively. The highest percentage of PCa cases $(40.2 \%)$ had a score $>2$ and $\leq 3$ points, while $34.8 \%$ controls had a score $>3$ and $\leq 4$ points. 
Table 2. Characteristics of controls and prostate cancer (PCa) cases in CAPLIFE study.

\begin{tabular}{|c|c|c|c|}
\hline & $\begin{array}{l}\text { Controls } \\
(n=302)\end{array}$ & $\begin{array}{c}\text { PCa Cases } \\
(n=398)\end{array}$ & $p$-Value \\
\hline Age (years), mean (SD) & $65.3(8.2)$ & $67.7(7.4)$ & $<0.01$ \\
\hline Age (years), $n(\%)$ & & & $<0.01$ \\
\hline $40-54$ & $39(12.9)$ & $21(5.3)$ & \\
\hline $55-69$ & $162(53.7)$ & $217(54.5)$ & \\
\hline $70-80$ & $101(33.4)$ & $160(40.2)$ & \\
\hline Education, $n(\%)$ & & & 0.38 \\
\hline Primary & $92(30.4)$ & $119(29.9)$ & \\
\hline Secondary & $147(48.7)$ & $211(53.0)$ & \\
\hline University & $63(20.9)$ & $68(17.1)$ & \\
\hline Energy intake (kcal/day), mean (SD) & $2438.1(705.7)$ & $2511.8(617.6)$ & 0.14 \\
\hline Alcohol consumption ${ }^{1}, n(\%)$ & & & 0.05 \\
\hline No consumption & $56(18.5)$ & $69(17.4)$ & \\
\hline Moderate & $215(71.2)$ & $262(65.8)$ & \\
\hline High & $31(10.3)$ & $67(16.8)$ & \\
\hline Smoking status, $n(\%)$ & & & 0.70 \\
\hline Never & $88(29.1)$ & $105(26.4)$ & \\
\hline Former & $157(52.0)$ & $212(53.3)$ & \\
\hline Current & $57(18.9)$ & $81(20.3)$ & \\
\hline First-degree family history of $\mathrm{PCa}^{2}, n(\%)$ & & & 0.46 \\
\hline No & $287(95.0)$ & $373(93.7)$ & \\
\hline Yes & $15(5.0)$ & $25(6.3)$ & \\
\hline \multicolumn{4}{|l|}{ Aggressiveness, $n(\%)$} \\
\hline ISUP $1-2$ & - & $307(77.1)$ & \\
\hline ISUP 3-5 & - & $91(22.9)$ & \\
\hline WCRF/AICR score, mean (SD) & $3.42(1.01)$ & $3.27(0.93)$ & 005 \\
\hline (Minimum-Maximum) & $(1.00-6.25)$ & $(0.75-6.25)$ & 0.05 \\
\hline WCRF/AICR score, $n(\%)$ & & & 0.08 \\
\hline$\leq 1$ & $1(0.3)$ & $3(0.7)$ & \\
\hline$>1-\leq 2$ & $27(8.9)$ & $30(7.6)$ & \\
\hline$>2-\leq 3$ & $98(32.4)$ & $160(40.2)$ & \\
\hline$>3-\leq 4$ & $105(34.8)$ & $132(33.2)$ & \\
\hline$>4-\leq 5$ & $51(16.9)$ & $63(15.8)$ & \\
\hline$>5-\leq 6$ & $18(6.0)$ & $8(2.0)$ & \\
\hline$>6-\leq 7$ & $2(0.7)$ & $1(0.5)$ & \\
\hline WCRF/AICR score ${ }^{3}, n(\%)$ & & & 0.69 \\
\hline Minimum compliance (T1) & $101(33.4)$ & $140(35.2)$ & \\
\hline Intermediate compliance (T2) & $111(36.8)$ & $151(37.9)$ & \\
\hline Maximum compliance (T3) & $90(29.8)$ & $107(26.9)$ & \\
\hline
\end{tabular}

SD, standard deviation. ${ }^{1}$ Categories based on 2018 WCRF/AICR recommendations on alcohol consumption (g/day). ${ }^{2}$ First-degree history of PCa in father and/or brothers. ${ }^{3}$ Minimum compliance (Tercile 1: $0.75-2.75$ points); intermediate compliance (Tercile 2: 3.00-3.75) and maximum compliance (Tercile 3: 4.00-6.25).

The distribution of controls' characteristics according to terciles of compliance with the score is provided in Table 3. Those participants with the highest compliance vs. subjects with the lowest compliance with the 2018 WCRF/AICR recommendations were older, had a lower energy intake, and had lower alcohol consumption (3.3\% with high alcohol consumption in controls with the highest compliance of the recommendations vs. $19.8 \%$ in controls with the lowest compliance; $p<0.01$ ). 
Table 3. Characteristics of participants in the control group according to terciles of the 2018 WCRF/AICR score in CAPLIFE study.

\begin{tabular}{|c|c|c|c|c|}
\hline & $\begin{array}{c}\text { Tercile } 1 \\
n=101\end{array}$ & $\begin{array}{c}\text { Tercile } 2 \\
n=111\end{array}$ & $\begin{array}{c}\text { Tercile } 3 \\
n=90\end{array}$ & \multirow{2}{*}{$p$-Value } \\
\hline & $\begin{array}{c}\min -\max \\
0.75-2.75\end{array}$ & $\begin{array}{c}\min -\max \\
3.00-3.75\end{array}$ & $\begin{array}{c}\min -\max \\
4.00-6.50\end{array}$ & \\
\hline Age (years), mean (SD) & $62.7(7.8)$ & $65.9(7.3)$ & $67.3(8.9)$ & 0.01 \\
\hline Age (years), $n(\%)$ & & & & 0.01 \\
\hline $40-54$ & $18(17.8)$ & $9(8.1)$ & $12(13.3)$ & \\
\hline $55-69$ & $62(61.4)$ & $64(57.7)$ & $36(40.0)$ & \\
\hline $70-80$ & $21(20.8)$ & $38(34.2)$ & $42(46.7)$ & \\
\hline Education, $n(\%)$ & & & & 0.74 \\
\hline Primary & $30(39.7)$ & $35(31.5)$ & $27(30.0)$ & \\
\hline Secondary & $54(53.5)$ & $51(46.0)$ & $42(46.7)$ & \\
\hline University & $17(16.8)$ & $25(22.5)$ & $21(23.3)$ & \\
\hline Energy intake (kcal/day), mean (SD) & $2510.5(720.0)$ & $2557.0(685.3)$ & $2210.3(668.4)$ & $<0.01$ \\
\hline Alcohol consumption ${ }^{1}, n(\%)$ & & & & $<0.01$ \\
\hline No consumption & $10(9.9)$ & $18(16.2)$ & $28(31.1)$ & \\
\hline Moderate & $71(70.3)$ & $85(76.6)$ & $59(65.6)$ & \\
\hline High & $20(19.8)$ & $8(7.2)$ & $3(3.3)$ & \\
\hline Smoking status, $n(\%)$ & & & & 0.26 \\
\hline Never & $22(21.8)$ & $37(33.3)$ & $29(32.2)$ & \\
\hline Former & $57(56.4)$ & $52(46.9)$ & $48(53.3)$ & \\
\hline Current & $22(21.8)$ & $22(19.8)$ & $13(14.4)$ & \\
\hline First-degree history of $\mathrm{PCa}^{2}, n(\%)$ & & & & 0.12 \\
\hline No & $98(97.0)$ & $107(96.4)$ & $82(91.1)$ & \\
\hline Yes & $3(3.0)$ & $3(3.6)$ & $8(8.9)$ & \\
\hline
\end{tabular}

SD, standard deviation. ${ }^{1}$ Categories based on WCRF/AICR recommendations on alcohol consumption (g/day).
${ }^{2}$ First-degree history of PCa in father and/or brothers.

When we analyzed the association with recommendation compliance, a slight protective relationship was observed between a higher compliance with the 2018 WCRF/AICR recommendations and PCa when this variable was analyzed as continuous (Table 4). For each unit of increase in the score, the risk of PCa was reduced by $19 \%$, aOR $=0.81(95 \%$ CI $0.69-0.96)(p$-value $=0.02)$. Its protective association is maintained when the $2018 \mathrm{WCRF} / \mathrm{AICR}$ score is considered as an ordinal variable in terciles, although without reaching statistical significance. The results are similar when we stratify by aggressiveness, aOR $=0.79(95 \%$ CI $0.66-0.95)$ and aOR $=0.86(95 \%$ CI $0.69-1.06)$ for each unit of increase in the score for low and high aggressiveness, respectively.

The mutually aOR for the individual components of the 2018 WCRF/AICR score and PCa are shown in Table 5. Three of the components of the score were independently associated with a lower risk of PCa: fast food and other processed foods, sugar-sweetened drinks, and alcohol consumption. Lower consumption of "fast foods' and other processed foods high in fat, starches or sugars, and sugar-sweetened drinks were associated with a lower risk of PCa, aOR $=0.63$ (95\% CI 0.42-0.64) and $\mathrm{aOR}=0.30(95 \%$ CI $0.12-0.77)$, respectively $(p$-trend $<0.05)$. Also, not consuming alcohol showed a protective association, $\mathrm{aOR}=0.49(95 \% \mathrm{CI} 0.27-0.91)$ for men who met with the recommendations ( $p$-trend $<0.05)$. Results according to aggressiveness are detailed in Supplementary Table S2 and similar results were obtained for all of the individual items; although these results should be taken with caution because of the sample size. 
Table 4. Association between $2018 \mathrm{WCRF} / \mathrm{AICR}$ score and PCa stratified by aggressiveness in CAPLIFE study.

\begin{tabular}{|c|c|c|c|c|c|c|c|}
\hline \multicolumn{8}{|c|}{ WCRF/AICR Score Categories } \\
\hline & $\begin{array}{c}\mathbf{N} \\
\text { Control/Cases }{ }^{1}\end{array}$ & $\begin{array}{c}\text { Tercile } 1 \\
\text { aOR }^{2}(95 \% \text { CI })\end{array}$ & $\begin{array}{c}\text { Tercile } 2 \\
\text { aOR }^{2}(95 \% \text { CI })\end{array}$ & $\begin{array}{c}\text { Tercile } 3 \\
\text { aOR }^{2}(95 \% \text { CI })\end{array}$ & $p$-Trend & $\begin{array}{l}\text { 1-Unit Increase } \\
\text { aOR }^{2}(95 \% \text { CI })\end{array}$ & $p$-Value \\
\hline \multicolumn{8}{|c|}{ Overall } \\
\hline & $302 / 398$ & 1.00 & $0.88(0.61-1.27)$ & $0.79(0.53-1.19)$ & 0.26 & $0.81(0.69-0.96)$ & 0.02 \\
\hline \multicolumn{8}{|c|}{ Aggressiveness $^{2}$} \\
\hline ISUP 1-2 & $302 / 307$ & 1.00 & $0.87(0.59-1.28)$ & $0.73(0.48-1.13)$ & 0.16 & $0.79(0.66-0.95)$ & 0.01 \\
\hline ISUP 3-5 & $302 / 91$ & 1.00 & $0.84(0.47-1.53)$ & $0.87(0.46-1.66)$ & 0.67 & $0.86(0.69-1.06)$ & 0.16 \\
\hline
\end{tabular}

${ }^{1} \mathrm{~N}$, number; $95 \% \mathrm{CI}, 95 \%$ confidence interval. ${ }^{2}$ aOR: Odds ratio adjusted for age, educational level, smoking status, First-degree family history of PCa and total energy intake.

Table 5. Mutually adjusted odds ratios and 95\% confidence intervals for PCa associated with the components of the 2018 WCRF/AICR score in CAPLIFE study.

\begin{tabular}{|c|c|c|c|}
\hline Components of the Score & N Controls/Cases & aOR $(95 \% \text { CI })^{1}$ & $p$-Trend \\
\hline 1. Be a healthy weight ${ }^{2}$ & & & 0.81 \\
\hline $0-0.25$ & $129 / 181$ & 1 & \\
\hline 0.5 & $85 / 87$ & $0.69(0.46-1.02)$ & \\
\hline $0.75-1$ & $88 / 130$ & $1.09(0.75-1.60)$ & \\
\hline 2. Be physical active & & & 0.63 \\
\hline 0 & $227 / 315$ & 1 & \\
\hline 0.5 & $17 / 14$ & $0.55(0.26-1.19)$ & \\
\hline 1 & $58 / 69$ & $0.94(0.62-1.44)$ & \\
\hline 3. Eat a diet rich in whole grains, vegetables, fruit and beans ${ }^{2}$ & & & 0.89 \\
\hline $0-0.25$ & $14 / 15$ & 1 & \\
\hline 0.5 & $16 / 26$ & $1.35(0.48-3.76)$ & \\
\hline $0.75-1$ & $272 / 357$ & $1.08(0.47-2.50)$ & \\
\hline $\begin{array}{l}\text { 4. Limit consumption of 'fast foods' and other processed foods } \\
\text { high in fat, starches or sugars }\end{array}$ & & & 0.02 \\
\hline 0 & $101 / 163$ & 1 & \\
\hline 0.5 & $100 / 125$ & $0.75(0.51-1.10)$ & \\
\hline 1 & $101 / 110$ & $0.63(0.42-0.94)$ & \\
\hline 5. Limit consumption of red and processed meat & & & 0.22 \\
\hline 0 & $231 / 297$ & 1 & \\
\hline 0.5 & $65 / 82$ & $0.96(0.63-1.46)$ & \\
\hline 1 & $6 / 19$ & $2.82(1.05-7.59)$ & \\
\hline 6. Limit consumption of sugar-sweetened drinks & & & 0.02 \\
\hline 0 & $7 / 25$ & 1 & \\
\hline 0.5 & $132 / 179$ & $0.39(0.16-0.97)$ & \\
\hline 1 & $163 / 194$ & $0.30(0.12-0.77)$ & \\
\hline 7. Limit alcohol consumption & & & 0.03 \\
\hline 0 & $31 / 67$ & 1 & \\
\hline 0.5 & $215 / 262$ & $0.57(0.34-0.95)$ & \\
\hline 1 & $56 / 69$ & $0.49(0.27-0.91)$ & \\
\hline
\end{tabular}

$\mathrm{N}$, number; $95 \% \mathrm{CI}, 95 \%$ confidence interval. ${ }^{1}$ aOR, Odds ratio adjusted for each individual component of the score and potential confounders (age, educational level, smoking status, primary family history of PCa and total energy intake). ${ }^{2}$ For recommendations based on subitem, the possible scores could be: $0,0.25,0.5,0.75$ and 1 , which were recategorized at $0-0.25,0.5$ and $0.75-1$.

\section{Discussion}

This case-control study explores the association between the 2018 WCRF/AICR Cancer Prevention Recommendations and the risk of $\mathrm{PCa}$, being one of the first studies in exploring this issue. A slight protective association was found between each one-unit increase of the 2018 WCRF/AICR score and the risk of PCa, especially for low aggressiveness PCa. In addition, three components of the 2018 WCRF/AICR score were independently associated with a lower risk of PCa: (i) "Fast foods" and other processed foods high in fat, starches or sugars; (ii) sugar-sweetened drinks; and (iii) alcohol.

If we compare the $2018 \mathrm{WCRF} / \mathrm{AICR}$ score with the previous recommendations, six of them partially coincide, while the following four recommendations have changed substantially: physical activity, 
alcohol intake, "fast foods" and other processed foods, and sugar-sweetened drinks [15]. In particular, we have found an association for three of the four changed recommendations. These changes permit a better definition of the recommendations and their characteristics, reducing the chances of misclassification. The physical activity recommendation of $\geq 30 \mathrm{~min} /$ day without indicating intensity was changed and subsequently considered only moderate-vigorous physical activity. In terms of alcohol consumption, the new recommendation supports a consumption equal to zero, instead of a daily intake of no more than two drinks for men in the 2007 WCRF/AICR recommendations. This recommendation is similar to the advice included in the European Code against Cancer [42]. Regarding foods and drinks that promote weight gain, the previous recommendation of 2007 is divided in two new recommendations: consumption of "fast foods" and other processed foods, and sugar-sweetened drinks.

To date the association between compliance with the 2018 WCRF/AICR recommendations and PCa has not been evaluated, but it has already been explored for the 2007 WCRF/AICR recommendations. The studies that use the previous recommendations do not find an association between these recommendations and PCa when the aggressiveness of the tumor is not considered [21-23,29,31]. The absence of predefined cut-off points for the different items of the 2007 recommendations might also have contributed to these negative results.

By stratifying for aggressiveness, a protective association between the cancer prevention recommendations and low aggressiveness PCa was observed; a finding not previously found by other researchers. For cases with a tumor with high aggressiveness, we also observed a protective effect, although the results do not reach the statistical significance. This may be due to the small sample size for high aggressiveness PCa in our study. In fact, other studies find similar results, MCC-Spain [22], where an inverse association was found for Gleason score $\geq 7$ cases (aOR $=0.85,95 \%$ CI 0.76-0.96, per 1-point increment in the WCRF/AICR score). A similar association (aOR $=0.87,95 \%$ CI 0.79-0.96, per 1-point increment in the WCRF/AICR score) was observed in the North Carolina-Louisiana Prostate Cancer Project [30].

Regarding limiting consumption of "fast foods" and other processed foods high in fat, starches or sugars, a recent cohort study, published in 2018, studied the association between "fast foods" and processed food and PCa risk [43]. This study found associations between ultra-processed foods and cancer in general, and breast cancer in particular; for PCa, no relation with consumption of fast food was observed, however only 281 PCa cases were analyzed.

For sugar-sweetened drinks and PCa, the results are also limited. According to a meta-analysis carried out with four observational studies conducted before 2012, the results are highly heterogeneous and they did not find an association between carbonated beverages and PCa [44]. In our study, we have considered both carbonated beverages and industrial sugar juices, and this difference could explain the inconsistent results. The French NutriNet-Santé prospective cohort (2009-2017) suggests a relationship between drink consumption and the total risk of cancer, producing an increase in the total risk of cancer of $18 \%$ per $100 \mathrm{~mL}$ per day [45]. In this cohort study, a higher risk is also observed for PCa, although it did not reach statistical significance because of a low sample size (291 PCa cases). Data on alcohol consumption and $\mathrm{PCa}$ is far more consistent, and a recent meta-analysis points to positive association for PCa; this risk starts even with a low volume consumption of alcohol (from $1.3 \mathrm{~g}$ per day) [46].

We found that PCa cases without a WCRF/AICR score had a lower educational level (Supplementary Table S1), as subjects with a lower educational level tend to have a lower compliance with recommendations, this would be underestimating the findings found. We may have been limited by the small sample size and lack of statistical power to detect significant associations, especially among high aggressiveness PCa cases. Finally, although we adjusted for a range of potential confounders which were associated with both the score and PCa risk, we cannot rule out the possibility of residual confounding.

Regarding advantages of our study, we have to point out the use of a previously validated FFQ for the Spanish population, including regional products [35]. In order to avoid possible changes in 
dietary habits after cancer diagnosis, we have only included incident cases before starting any type of treatment for PCa. In addition, the approach using the 2018 WCRF/AICR recommendations permits the evaluation of diet as a whole, accounting for possible synergistic effects between nutrients and foods on cancer risk, and it also incorporates physical activity and body fatness; hence being an indicator of an overall healthy lifestyle. As an additional strength of our study, the 2018 WCRF/AICR recommendations have been based on a standardized scoring system [16], allowing the construction of comparable and solid cut-off points for each recommendation, a problem found in the previous applications of this score. It is also noteworthy, that most of the participants of the CAPLIFE study had detailed information about the diet and plausible energy intake which allowed the construction of the score for $89.4 \%$ of PCa cases and $91.2 \%$ of controls.

\section{Conclusions}

In conclusion, in this Spanish population-based case-control study, a slight protective association was found between compliance with the 2018 World Cancer Research Fund/American Institute for Cancer Research (WCRC/AICR) cancer prevention recommendations on diet, physical activity, and body fatness and overall PCa, especially in low aggressiveness PCa. In addition, limiting consumption of "fast foods" and other processed foods high in fat, starches or sugars, sugar-sweetened drinks, and alcohol were independently associated with lower risk of PCa. Altogether, it is advisable to comply with healthy lifestyles in the prevention of PCa.

Supplementary Materials: The following are available online at http://www.mdpi.com/2072-6643/12/3/768/s1. Table S1: Characteristics of controls and PCa cases with and without WCRF/AICR score in CAPLIFE study. Table S2: Mutually adjusted odds ratios and 95\% confidence intervals for low and high aggressiveness PCa associated with the components of the 2018 WCRF/AICR score in CAPLIFE study.

Author Contributions: J.-M.J.-J. and O.-R.R. conceived and designed the study. O.-R.R., L.-L.M., and S.-B.I. analyzed data. O.-R.R., J.-P.A., V.-A.F., G.-C.M., and S.M.-J. coordinated data collection. The first draft of the paper was written by O.-R.R., L.-L.M., and J.-M.J.-J. All authors have read and agreed to the published version of the manuscript

Funding: This research was funded by Regional Ministry of Health of Andalusia/Consejería de Salud of the Junta de Andalucía (PI-0514-2016) and Instituto de Salud Carlos III-FEDER (PI15/00914).

Acknowledgments: We thank all subjects who participated in the study and all CAPLIFE collaborators and the Ingrid de Ruiter, $\mathrm{MBChB}$, for English language and editing support. The results of this study are part of the doctoral thesis of Macarena Lozano-Lorca.

Conflicts of Interest: The authors declare no conflict of interest. The funders had no role in the design of the study; in the collection, analyses, or interpretation of data; in the writing of the manuscript, or in the decision to publish the results.

\section{References}

1. Bray, F.; Ferlay, J.; Soerjomataram, I.; Siegel, R.L.; Torre, L.A.; Jemal, A. Global cancer statistics 2018: GLOBOCAN estimates of incidence and mortality worldwide for 36 cancers in 185 countries. CA Cancer J. Clin. 2018, 68, 394-424. [CrossRef] [PubMed]

2. Rawla, P. Epidemiology of Prostate Cancer. World J. Oncol. 2019, 10, 63-89. [CrossRef] [PubMed]

3. Ferlay, J.; Colombet, M.; Soerjomataram, I.; Dyba, T.; Randi, G.; Bettio, M.; Gavin, A.; Visser, O.; Bray, F. Cancer incidence and mortality patterns in Europe: Estimates for 40 countries and 25 major cancers in 2018. Eur. J. Cancer 2018, 103, 356-387. [CrossRef] [PubMed]

4. Quinn, M.; Babb, P. Patterns and trends in prostate cancer incidence, survival, prevalence and mortality. Part I: International comparisons. BJU Int. 2002, 90, 162-173. [CrossRef] [PubMed]

5. Eeles, R.A.; Al Olama, A.A.; Benlloch, S.; Saunders, E.J.; Leongamornlert, D.A.; Tymrakiewicz, M.; Ghoussaini, M.; Luccarini, C.; Dennis, J.; Jugurnauth-Little, S.; et al. Identification of 23 new prostate cancer susceptibility loci using the iCOGS custom genotyping array. Nat. Genet. 2013, 45, 385-391. [CrossRef] [PubMed]

6. Tan, S.-H.; Petrovics, G.; Srivastava, S. Prostate Cancer Genomics: Recent Advances and the Prevailing Underrepresentation from Racial and Ethnic Minorities. Int. J. Mol. Sci. 2018, 19, 1255. [CrossRef] 
7. Chen, H.; Yu, H.; Wang, J.; Zhang, Z.; Gao, Z.; Chen, Z.; Lu, Y.; Liu, W.; Jiang, D.; Zheng, S.L.; et al. Systematic enrichment analysis of potentially functional regions for 103 prostate cancer risk-associated loci. Prostate 2015, 75, 1264-1276. [CrossRef]

8. Ballon-Landa, E.; Parsons, J.K. Nutrition, physical activity, and lifestyle factors in prostate cancer prevention. Curr. Opin. Urol. 2018, 28, 55-61. [CrossRef]

9. Papadimitriou, N.; Muller, D.; Van Den Brandt, P.A.; Geybels, M.; Patel, C.J.; Gunter, M.J. A nutrient-Wide association study for risk of prostate cancer in the European Prospective Investigation into Cancer and Nutrition and the Netherlands Cohort Study. Eur. J. Nutr. 2019. [CrossRef]

10. Markozannes, G.; Tzoulaki, I.; Karli, D.; Evangelou, E.; Ntzani, E.; Gunter, M.J.; Norat, T.; Ioannidis, J.P.; Tsilidis, K.K. Diet, body size, physical activity and risk of prostate cancer: An umbrella review of the evidence. Eur. J. Cancer 2016, 69, 61-69. [CrossRef]

11. Baena, R.; Salinas, P. Diet and colorectal cancer. Maturitas 2015, 80, 258-264. [CrossRef] [PubMed]

12. Harvie, M.; Howell, A.; Evans, D.G. Can diet and lifestyle prevent breast cancer: What is the evidence? Am. Soc. Clin. Oncol. Educ. Book Am. Soc. Clin. Oncol. Annu. Meet. 2015, 35, e66-e73. [CrossRef] [PubMed]

13. Glade, M.J. Food, nutrition, and the prevention of cancer: A global perspective. American Institute for Cancer Research/World Cancer Research Fund, American Institute for Cancer Research, 1997. Nutrition 1999, 15, 523-526. [PubMed]

14. Wiseman, M. The second World Cancer Research Fund/American Institute for Cancer Research expert report. Food, nutrition, physical activity, and the prevention of cancer: A global perspective. Proc. Nutr. Soc. 2008, 67, 253-256. [CrossRef] [PubMed]

15. World Cancer Research Fund/American Institute for Cancer Research. Diet, Nutrition, Physical Activity and Cancer: A Global Perspective. Continuous Update Project Expert Report 2018. Available online: http://dietandcancerreport.org (accessed on 11 October 2019).

16. Shams-White, M.M.; Brockton, N.T.; Mitrou, P.; Romaguera, D.; Brown, S.; Bender, A.; Kahle, L.L.; Reedy, J. Operationalizing the 2018 World Cancer Research Fund/American Institute for Cancer Research (WCRF/AICR) Cancer Prevention Recommendations: A Standardized Scoring System. Nutrients 2019, 11, 1572. [CrossRef]

17. Lohse, T.; Faeh, D.; Bopp, M.; Rohrmann, S. Adherence to the cancer prevention recommendations of the World Cancer Research Fund/American Institute for Cancer Research and mortality: A census-linked cohort. Am. J. Clin. Nutr. 2016, 104, 678-685. [CrossRef]

18. Jankovic, N.; Geelen, A.; Winkels, R.M.; Mwungura, B.; Fedirko, V.; Jenab, M.; Illner, A.K.; Brenner, H.; Ordóñez-Mena, J.M.; Kiefte de Jong, J.C.; et al. Adherence to the WCRF/AICR Dietary Recommendations for Cancer Prevention and Risk of Cancer in Elderly from Europe and the United States: A Meta-Analysis within the CHANCES Project. Cancer Epidemiol. Biomark. Prev. 2017, 26, 136-144. [CrossRef]

19. Hastert, T.A.; Beresford, S.A.A.; Patterson, R.E.; Kristal, A.R.; White, E. Adherence to WCRF/AICR Cancer Prevention Recommendations and Risk of Postmenopausal Breast Cancer. Cancer Epidemiol. Biomark. Prev. 2013, 22, 1498-1508. [CrossRef]

20. Castelló, A.; Martín, M.; Ruiz, A.; Casas, A.M.; Baena-Cañada, J.M.; Lope, V.; Antolín, S.; Sánchez, P.; Ramos, M.; Antón, A.; et al. Lower Breast Cancer Risk among Women following the World Cancer Research Fund and American Institute for Cancer Research Lifestyle Recommendations: EpiGEICAM Case-Control Study. PLoS ONE 2015, 10, e0126096. [CrossRef]

21. Makarem, N.; Lin, Y.; Bandera, E.V.; Jacques, P.F.; Parekh, N. Concordance with World Cancer Research Fund/American Institute for Cancer Research (WCRF/AICR) guidelines for cancer prevention and obesity-related cancer risk in the Framingham Offspring cohort (1991-2008). Cancer Causes Control 2015, 26, 277-286. [CrossRef]

22. Romaguera, D.; Gracia-Lavedan, E.; Molinuevo, A.; de Batlle, J.; Mendez, M.; Moreno, V.; Vidal, C.; Castelló, A.; Pérez-Gómez, B.; Martín, V.; et al. Adherence to nutrition-based cancer prevention guidelines and breast, prostate and colorectal cancer risk in the MCC-Spain case-control study. Int. J. Cancer 2017, 141, 83-93. [CrossRef] [PubMed]

23. Schulpen, M.; van den Brandt, P.A. Adherence to the Mediterranean Diet and Risks of Prostate and Bladder Cancer in the Netherlands Cohort Study. Cancer Epidemiol. Biomark. Prev. 2019, 28, 1480-1488. [CrossRef] [PubMed] 
24. Karavasiloglou, N.; Husing, A.; Masala, G.; van Gils, C.H.; Turzanski Fortner, R.; Chang-Claude, J.; Huybrechts, I.; Weiderpass, E.; Gunter, M.; Arveux, P.; et al. Adherence to the World Cancer Research Fund/American Institute for Cancer Research cancer prevention recommendations and risk of in situ breast cancer in the European Prospective Investigation into Cancer and Nutrition (EPIC) cohort. BMC Med. 2019, 17, 221. [CrossRef] [PubMed]

25. Turati, F.; Bravi, F.; Di Maso, M.; Bosetti, C.; Polesel, J.; Serraino, D.; Dalmartello, M.; Giacosa, A.; Montella, M.; Tavani, A.; et al. Adherence to the World Cancer Research Fund/American Institute for Cancer Research recommendations and colorectal cancer risk. Eur. J. Cancer 2017, 85, 86-94. [CrossRef] [PubMed]

26. Bravi, F.; Polesel, J.; Garavello, W.; Serraino, D.; Negri, E.; Franchin, G.; La Vecchia, C.; Bosetti, C. Adherence to the World Cancer Research Fund/American Institute for Cancer Research recommendations and head and neck cancers risk. Oral Oncol. 2017, 64, 59-64. [CrossRef] [PubMed]

27. Lucas, A.L.; Bravi, F.; Boffetta, P.; Polesel, J.; Serraino, D.; La Vecchia, C.; Bosetti, C. Adherence to World Cancer Research Fund/American Institute for Cancer Research recommendations and pancreatic cancer risk. Cancer Epidemiol. 2016, 40, 15-21. [CrossRef]

28. Solans, M.; Romaguera, D.; Gracia-Lavedan, E.; Molinuevo, A.; Benavente, Y.; Saez, M.; Marcos-Gragera, R.; Costas, L.; Robles, C.; Alonso, E.; et al. Adherence to the 2018 WCRF/AICR cancer prevention guidelines and chronic lymphocytic leukemia in the MCC-Spain study. Cancer Epidemiol. 2019, 64, 101629. [CrossRef]

29. Romaguera, D.; Vergnaud, A.-C.; Peeters, P.H.; van Gils, C.H.; Chan, D.S.; Ferrari, P.; Romieu, I.; Jenab, M.; Slimani, N.; Clavel-Chapelon, F.; et al. Is concordance with World Cancer Research Fund/American Institute for Cancer Research guidelines for cancer prevention related to subsequent risk of cancer? Results from the EPIC study. Am. J. Clin. Nutr. 2012, 96, 150-163. [CrossRef]

30. Arab, L.; Su, J.; Steck, S.E.; Ang, A.; Fontham, E.T.H.; Bensen, J.T.; Mohler, J.L. Adherence to World Cancer Research Fund/American Institute for Cancer Research lifestyle recommendations reduces prostate cancer aggressiveness among African and Caucasian Americans. Nutr. Cancer 2013, 65, 633-643. [CrossRef]

31. Er, V.; Lane, J.A.; Martin, R.M.; Emmett, P.; Gilbert, R.; Avery, K.N.L.; Walsh, E.; Donovan, J.L.; Neal, D.E.; Hamdy, F.C.; et al. Adherence to dietary and lifestyle recommendations and prostate cancer risk in the prostate testing for cancer and treatment (ProtecT) trial. Cancer Epidemiol. Biomark. Prev. 2014, 23, 2066-2077. [CrossRef]

32. Loeb, S.; Bjurlin, M.A.; Nicholson, J.; Tammela, T.L.; Penson, D.F.; Carter, H.B.; Carroll, P.; Etzioni, R. Overdiagnosis and overtreatment of prostate cancer. Eur. Urol. 2014, 65, 1046-1055. [CrossRef] [PubMed]

33. ICD-10 Version: 2016. Available online: https://icd.who.int/browse10/2016/en (accessed on 20 January 2020).

34. Román Viñas, B.; Ribas Barba, L.; Ngo, J.; Serra Majem, L. Validación en población catalana del cuestionario internacional de actividad física. Gac. Sanit. 2013, 27, 254-257. [CrossRef] [PubMed]

35. Martin-Moreno, J.M.; Boyle, P.; Gorgojo, L.; Maisonneuve, P.; Fernandez-Rodriguez, J.C.; Salvini, S.; Willett, W.C. Development and validation of a food frequency questionnaire in Spain. Int. J. Epidemiol. 1993, 22, 512-519. [CrossRef] [PubMed]

36. Tablas de composición de alimentos del CESNID. Available online: http://www.sennutricion.org/es/2013/05/ 13/tablas-de-composicin-de-alimentos-del-cesnid (accessed on 7 November 2019).

37. Willett, W. Nutritional Epidemiology; Oxford University Press: Oxford, UK, 2013; ISBN 9780199979448.

38. Monteiro, C.A.; Cannon, G.; Levy, R.; Moubarac, J.-C.; Jaime, P.; Paula Martins, A.; Canella, D.; Louzada, M.; Parra Also with Camila Ricardo, D.; Calixto, G.; et al. NOVA. The star shines bright. World Nutr. 2016, 7, 28-38.

39. Epstein, J.I. An Update of the Gleason Grading System. J. Urol. 2010, 183, 433-440. [CrossRef] [PubMed]

40. Epstein, J.I.; Egevad, L.; Amin, M.B.; Delahunt, B.; Srigley, J.R.; Humphrey, P.A. The 2014 International Society of Urological Pathology (ISUP) Consensus Conference on Gleason Grading of Prostatic Carcinoma: Definition of Grading Patterns and Proposal for a New Grading System. Am. J. Surg. Pathol. 2016, 40, $244-252$. [CrossRef]

41. Neuzillet, Y.; Raynaud, J.-P.; Dreyfus, J.-F.; Radulescu, C.; Rouanne, M.; Schneider, M.; Krish, S.; Roupret, M.; Drouin, S.J.; Comperat, E.; et al. Aggressiveness of Localized Prostate Cancer: The Key Value of Testosterone Deficiency Evaluated by Both Total and Bioavailable Testosterone: AndroCan Study Results. Horm. Cancer 2019, 10, 36-44. [CrossRef]

42. Pérula de Torres, L.A.; Espina García, C. What is the European Code against Cancer, who knows it and why it serves? Aten. Primaria 2018, 50,71-73. [CrossRef] 
43. Fiolet, T.; Srour, B.; Sellem, L.; Kesse-Guyot, E.; Alles, B.; Mejean, C.; Deschasaux, M.; Fassier, P.; Latino-Martel, P.; Beslay, M.; et al. Consumption of ultra-processed foods and cancer risk: Results from NutriNet-Sante prospective cohort. BMJ 2018, 360, k322. [CrossRef]

44. Boyle, P.; Koechlin, A.; Autier, P. Sweetened carbonated beverage consumption and cancer risk: Meta-analysis and review. Eur. J. Cancer Prev. 2014, 23, 481-490. [CrossRef]

45. Chazelas, E.; Srour, B.; Desmetz, E.; Kesse-Guyot, E.; Julia, C.; Deschamps, V.; Druesne-Pecollo, N.; Galan, P.; Hercberg, S.; Latino-Martel, P.; et al. Sugary drink consumption and risk of cancer: Results from NutriNet-Santé prospective cohort. BMJ 2019, 366, 12408. [CrossRef] [PubMed]

46. Zhao, J.; Stockwell, T.; Roemer, A.; Chikritzhs, T. Is alcohol consumption a risk factor for prostate cancer? A systematic review and meta-analysis. BMC Cancer 2016, 16, 845. [CrossRef] [PubMed]

C 2020 by the authors. Licensee MDPI, Basel, Switzerland. This article is an open access article distributed under the terms and conditions of the Creative Commons Attribution (CC BY) license (http://creativecommons.org/licenses/by/4.0/). 